\title{
Protagonismo da mulher negra: uma discussão sobre igualdade de gênero e a redução das desigualdades
}

\author{
Protagonism of black women: a discussion on gender equality and the reduction of inequalities \\ Protagonismo de la mujer negra: una discusión sobre igualdad de género y reducción de
}

desigualdades

Recebido: 01/10/2021 | Revisado: 09/11/2021 | Aceito: 09/11/2021 | Publicado: 15/11/2021

\author{
Rosilene das Graças Santos \\ ORCID: https://orcid.org/0000-0002-0012-1510 \\ Faculdade Patos de Minas, Brasil. \\ E-mail: rosilene-santos2@ hotmail.com \\ Regina Celia de Souza Beretta \\ ORCID: https://orcid.org/0000-0003-2817-0805 \\ Universidade de Franca, Brasil \\ E-mail: regina.beretta@unifran.edu.br \\ Gilmar Antoniassi Junior \\ ORCID: https://orcid.org/0000-0002-1809-1380 \\ Universidade de Franca, Brasil \\ Faculdade Patos de Minas, Brasil \\ Faculdade Cidade de João Pinheiro, Brasil \\ E-mail: jrantoniassi@ hotmail.com
}

\begin{abstract}
Resumo
O objetivo deste estudo foi de discutir o protagonismo da mulher negra acerca da igualdade de gênero e da redução das desigualdades. Utilizou-se um delineamento qualitativo de estudo de caso de natureza exploratória através do método de história de vida, mediante a narrativa da minissérie a vida e a história de Madam C.J. Walker, produzido por DeMane Davis, Eric Oberland e Lena Cordina. A minissérie conta a história da primeira estadunidense a se tornar milionária por conta própria, fazendo seu próprio negócio, ganhando todo o dinheiro através de seu trabalho, caracterizado pela produção e venda de produtos para cuidados com o cabelo. Foi possível constatar através das reflexões que ao desenvolver o elixir capilar demonstrou que uma mulher negra pode participar efetivamente do mercado do trabalho, pode ocupar espaços públicos da mesma forma que os homens e alçar voos empreendendo.

Palavras-chave: Mulheres; Pretas; Protagonismo; Igualdade de gênero.
\end{abstract}

\begin{abstract}
The aim of this study was to discuss the role of black women regarding gender equality and the reduction of inequalities. A qualitative exploratory case study design was used through the life history method, through the narrative of the miniseries the life and history of Madam CJ Walker, produced by DeMane Davis, Eric Oberland and Lena Cordina. The miniseries tells the story of the first American to become a millionaire on her own, making her own business, earning all the money through her work, characterized by the production and sale of hair care products. It was possible to see through the reflections that by developing the capillary elixir, it showed that a black woman can effectively participate in the labor market, can occupy public spaces in the same way as men and take flight by undertaking.

Keywords: Women; Black; Protagonism; Gender equality.

\section{Resumen}

El objetivo de este estudio fue discutir el papel de las mujeres negras en la igualdad de género y la reducción de las desigualdades. Se utilizó un diseño de estudio de caso exploratorio cualitativo a través del método de historia de vida, a través de la narrativa de la miniserie La vida e historia de Madam C.J. Walker, producida por DeMane Davis, Eric Oberland y Lena Cordina. La miniserie cuenta la historia de la primera estadounidense en convertirse en millonaria por su cuenta, haciendo su propio negocio, ganando todo el dinero con su trabajo, caracterizado por la producción y venta de productos para el cuidado del cabello. Se pudo ver a través de las reflexiones que al desarrollar el elixir capilar, se demostró que una mujer negra puede participar efectivamente en el mercado laboral, puede ocupar los espacios públicos de la misma manera que los hombres y emprender el vuelo.
\end{abstract}

Palabras clave: Mujeres; Negro; Protagonismo; Igualdad de género. 


\section{Introdução}

A Constituição da República promulgada em 1988 (Constituição Federal, 2021), também denominada Constituição Cidadã, consagra que homens e mulheres, independente de raça, são considerados iguais, conforme preceitua o artigo $5^{\circ}$, inciso $\mathrm{I}^{1}$.

Contudo, por mais que a igualdade seja um mandamento constitucional, o que se constata é que existe a necessidade da efetivação desse direito de forma material, para consolidação das oportunidades visando nivelar desníveis, ou seja: que a igualdade alcance as estruturas da sociedade (Figueiredo, 2018).

Com efeito, a atual conjuntura da mulher negra no Brasil, ainda traz resquícios da sociedade escravocrata do país antes de 1988, enquanto perdurava a ditadura. Para Santos (2002, p. 132), "o negro tornou-se cidadão indesejado, cidadão por acaso, por força e vontade branca, o negro deveria resignar-se à sua condição de estranho à civilidade, de outro indesejável.”. Deste modo, os negros ainda vivem em situação de marginalização, o que demonstra que no Brasil ainda perdura uma democracia racial falsa, refletindo um preconceito velado, o que dificulta, inclusive, a consciência da discriminação e o seu combate.

Conforme entendimento de Carneiro (2003), há séculos, a mulher negra experimenta essa marca quando tenta se introduzir no mercado de trabalho. Infelizmente, a mulher negra é aceita no mercado de trabalho para desempenhar trabalhos autônomos ou subempregos, o que reflete em vários fatores de sua vida, como: saúde, educação, poder aquisitivo e acesso à informação, principalmente a digital.

Atualmente, a mulher negra possui uma carga de trabalho maior, enfrenta empecilhos do preconceito, inclusive para encontrar um parceiro para fins amorosos (Roland, 1993).

Nos últimos anos, pesquisas têm evidenciado que a desigualdade racial no Brasil é patente, principalmente na região sudeste, quando se considera a problemática da questão racial e a solidificação do capitalismo no Brasil. Além disso, foi apontado que as mulheres negras entram no mercado de trabalho, em tenra idade, experimentam o fantasma do desemprego e auferem menores salários (Bento, 1995).

Segundo dados do IBGE, a participação de negros na sociedade alcançou 52,9\%, estimando-se 107 milhões de indivíduos, totalizando aproximadamente 201 milhões brasileiros. A população negra também integra 52,8\% dos ativos economicamente e de 51,9\% da população ocupada (IBGE, 2021). Aliás, ao se tratar de ações afirmativas ou de inclusão nas organizações, constata-se que não se alcançou um nível apropriado, tendo em vista que negros e pardos constituem mais da metade dos brasileiros.

Conforme magistério de Bento (1995), o preconceito em desfavor de mulheres negras, notadamente as que ocupam cargos de chefia, se dá pela recalcitrância do homem branco em admitir alguém que foi anos considerada subordinada, digna apenas de funções e empregos sem evidência social. A superioridade social baseada em condições de raça e gênero, determina que existe uma posição inferior de brancos e negros, homens e mulheres e isso deve se refletir no trabalhar, ou seja, negros devem ocupar funções inferiores.

Do mesmo modo, constata-se que as mulheres negras perseguem meios alternativos para conseguir promover o sustento da família. Outrossim, 50\% das mulheres são arrimo de família. Essas formas alternativas de sustento são muitas vezes, a venda de doces, quitutes e artesanato, em pese muitas delas terem estudos e qualificações profissionais (Bento, 1995). É dessa forma que o racismo estrutural perdura na sociedade. As mulheres negras precisam constantemente validar suas

\footnotetext{
${ }^{1}$ Art. $5^{\circ}$ Todos são iguais perante a lei, sem distinção de qualquer natureza, garantindo-se aos brasileiros e aos estrangeiros residentes no País a inviolabilidade do direito à vida, à liberdade, à igualdade, à segurança e à propriedade, nos termos seguintes: I - homens e mulheres são iguais em direitos e obrigações, nos termos desta Constituição; [...]
} 
aptidões perante o homem branco. Em razão do gênero e da raça, precisam esforçarem-se muito mais que as brancas. A luta é diária, cansativa e perene (Madalozzo, Martins \& Shiratori, 2021).

Por conseguinte, o presente estudo justifica-se pela necessidade de dialogar sobre os aspectos que contemplem a redução das desigualdades no tocante ao protagonismo da mulher. A mulher por sua natureza ela tem assumido diferentes papéis na sociedade, sendo mães, esposas, estudantes, trabalhadoras e muitas cuidadoras do lar e da família, vivenciando as sim a dupla jornada de trabalho. Esse movimento dar-se-á devido a necessidade de aumentar o orçamento doméstico familiar, pois muitas famílias são sustentadas por mulheres; assim à medida em que elas vão obtendo mais conhecimento por meio da formação acadêmica e profissional, esta mulher vai se tornando cada vez mais independente (Antoniassi Junior \& Figueiredo, 2020); (Madalozzo, Martins \& Shiratori, 2021). Acumulando diferentes papéis elas passam a ter diversas responsabilidades em relação as posições ocupadas, observa-se que o desempenho de atividades rotineiras é passadas despercebidas na sociedade sem atribuição de valor social, embora a mulher tenha adentrado no mercado de trabalho as adversidades enfrentadas por elas no dia a dia é o que seu estado de bem-estar (Possatti \& Dias, 2002).

Dado isso, o objetivo deste estudo é de discutir o protagonismo da mulher negra acerca da igualdade de gênero e da redução das desigualdades, à luz da minissérie a vida e a história de Madam C.J. Walker.

\section{Metodologia}

Utilizou-se um delineamento qualitativo de natureza descritiva histórica reflexiva através do método de história de vida, baseada na história real narrada na minissérie 'A vida e a história de Madam C.J. Walker', uma mulher afro-americana que venceu a pobreza, construiu um império de produtos de beleza e se tornou a primeira milionária pelo próprio esforço (Asher, Davis, Oberland, \& Cordina, 2020; Ludke \& André, 2013).

A escolha da minissérie se deu por se tratar de uma comovente história de uma ativista social e primeira mulher e por ela conquistar a sua própria fortuna por meio de uma linha de produtos capilares e cosméticos para mulheres negras.

Os achados foram analisados, corroborados através da observação no tocante ao feminino - o contexto social e de vida - negritude - empreendedorismo; articulado com o referencial teórico que permita discutir o protagonismo da mulher ante as adversidades visando a redução das desigualdades.

\subsection{A História de Madam C. J. Walker - Breve relato da série}

A minissérie “A Vida e a História de Madam C.J. Walker” conta a história da primeira estadunidense a se tornar milionária por conta própria, fazendo seu próprio negócio, ganhando todo o dinheiro através de seu trabalho, caracterizado pela produção e venda de produtos para cuidados com o cabelo, sua marca ficou conhecida como Madam Walker.

Madam Walker nasceu em 1867, quatro anos após abolição da escravatura nos Estados Unidos, filha de pais escravizados, ficou órfã aos 7 anos, foi morar com sua irmã, casou-se aos 14 anos e viveu um relacionamento onde era abusada pelo marido. Começou a lavar roupas para fora para ter como se sustentar, e devido ao trabalho, não conseguiu estudar. Mesmo assim se alfabetizou graças aos cultos dominicais que frequentava na igreja.

Em 1885 teve sua filha Lilian, em seu segundo relacionamento, dois anos depois ficou viúva. A rotina dura, a falta de condições sanitárias, e a forte química dos produtos usados para lavar as roupas e uma alimentação sem nutrientes, fez com que Sarah começasse a ter uma severa queda de cabelo, deixando-a com a autoestima abalada, o que trouxe ainda mais preconceito e julgamento das pessoas a sua volta. Cresceu e viveu em uma época em que os negros estavam começando a adquirir os mesmos direitos que os brancos e ganhando espaço no mundo dos negócios. Após o grande abalo psicológico causado pela queda do cabelo, Sarah foi em busca de informações sobre os cuidados com o cabelo, e conheceu a Annie que produzia produtos para cabelo para afro-americanas, se tornou usuária dos produtos, e isso ajudou muito a recuperar seu cabelo 
e autoestima. Então propôs a Annie que fizesse a venda daqueles produtos, e saiu para o mercado. Percebendo a quantidade do público que conseguiria atingir Sarah desenvolveu com base no produto de Annie uma fórmula que possibilitasse um crescimento saudável e uma aparência mais bonita para os cabelos de mulheres negras e fosse oferecido por um preço acessível aquelas mulheres, o que ocasionou uma acusação de Sarah ter copiado a fórmula de Annie, mas sem comprovação de tal situação.

Nessa jornada, Sarah conheceu Sidney Walker, com quem se casou, foi uma pessoa importante para o negócio e desenvolvimento dos produtos. Em sua abordagem de vendas porta a porta Sarah destacava seu produto e contava sua experiência pessoal, após a recuperação de seu cabelo e bem-estar. Todo esse trabalho evoluiu para abertura de um salão de beleza, a colaboração do marido com a promoção dos produtos e a dedicação da filha em ajudar na aplicação em suas clientes ajudou no sucesso do negócio. Sarah então decide deixar o local ondo iniciou para abranger seu negócio, deixando sua filha no comando. Pensando sempre em crescer e reinvestindo a maior parte de seus lucros, foi em busca de revendedoras e representantes em novas partes do estado. Depois de ficar ausente por algumas oportunidades de negócios, seu casamento com Sidney ficou insustentável, o que ocasionou em uma separação.

Sarah conquista um mercado e pensando não apenas na capacitação profissional das novas colaboradoras a empreendedora era uma forte defensora da independência econômica das mulheres negras, abriu programa formação de vendedoras comissionaria, ensinando o sistema de vendas Walker, o que ajudou várias mulheres alcançarem suas rendas familiares, sempre incentivando as mulheres. Através de uma opinião da filha de abrir um salão em Nova Iorque, Sarah alcança grande sucesso, pensando em inovar, cria um complemento de produtos para cabelo juntamente com acessórios para o cuidado, como exemplo o pente quente. Com todo esse empenho e ideias inovadoras, as vendas foram aumentando e os produtos Walker ficaram cada vez mais conhecidos.

Sarah contou com apoio de grandes empreenderes, utilizando todo seu sucesso a seu favor, mas sem deixar de ser a grande força de seu empreendimento. Entre 1911 e 1917 sua empresa atingiu seu ápice, empregando milhares de mulheres. Desfrutou de sua fortuna comprando uma mansão ao lado do homem mais rico dos tempos, ajudava instituições filantrópicas, realizava várias doações para comunidades afro-americanas entre outros movimentos sociais. Em maio de 1919, com apenas 51 anos veio falecer vítima de uma falência renal e complicações devia a hipertensão. Depois de sua morte sua filha Lilian assumiu os negócios, nos anos 20 a marca atingiu além dos Estados Unidos (EUA) e teve êxito por um longo tempo e vigorou até 1981 .

\section{Análise e Discussão}

A minissérie “A Vida e a História de Madam C.J. Walker” aborda temáticas polêmicas no que diz respeito ao racismo e a luta por igualdade de direitos da população negra, em especial das mulheres. A obra narra os obstáculos enfrentados no período pós-abolição, como subempregos destinados aos negros, demonstrando claramente que as opções eram trabalhos safristas, de mão-de-obra de obra pesada, sem que pudessem desenvolver talentos pessoais. Aos negros mais "privilegiados" sobravam ocupações em casas de seus antigos senhorios, onde trabalhavam como lavadeiras, passadeiras, jardineiros, motoristas etc. Enfatize-se, também, que a remuneração era menor que a dos brancos, especialmente considerando a dos homens brancos (Momesso e Hidaka, 2021).

Além do mais, mais de 25 anos depois de abolição da escravidão, muitas mulheres negras ainda trabalhavam no campo. De acordo com esse cenário, algumas mulheres conseguiam trabalhar em casas grandes exercendo atividades domésticas, outras, no entanto viam portas sendo fechadas nos demais setores (Hooks, 2015).

Em pese isso, com muita luta e resistência, um número ínfimo de mulheres negras, ainda lutava para integrarem-se no mercado de trabalho, como vendedoras, recepcionistas ou cozinheiras em hotéis (Werneck, 2016). 
Uma questão muito importante abordada na minissérie é o racismo, a humilhação e desafios da população negra perante "superioridade branca". Um fato que merece atenção é o assassinato do personagem Sweetness que é morto por um grupo de homens brancos, em virtude do preconceito racial.

A obra também desperta debates sobre o colorismo, fenômeno que ocorre quando a tonalidade da pele determina onde a população negra é aceita na sociedade (Hooks, 2015). Um grande exemplo disso, é quando Annie recusa Sarah como uma de suas vendedoras, por ela ser de cor negra, o que simbolizava à época, que ela possuía um patamar inferior.

Acontece que ser uma mulher negra com uma tonalidade mais branca traduz apenas um privilégio mascarado, pois todos da sociedade sabiam que esse fenômeno somente ocorria em razão dos estupros dos escravagistas, desencadeando a miscigenação de raças. Enfatize-se, que no período colonial existia uma hipersexualização da mulher negra e isso funcionava como moeda de troca, sendo a mulher um mero objeto de propriedade de seus senhores. A dignidade da pessoa humana não era aplicada aos negros (Werneck, 2016).

Ao publicar sua tese de doutorado intitulada "Brancas de almas negras? beleza, racialização e cosmética na imprensa negra pós-emancipação (EUA, 1890-1930)" Côrtes (2012) descreveu que Madam C. J. Walker venceu os obstáculos do preconceito e da estigmatização social, em virtude de sua obstinação e resistência. Sarah agiu como uma heroína e se colocava em pé de igualdade com os homens negros, podendo ser comparada com Frederick Douglass e Paul Laurence Dunbar.

Em uma convecção promovida por Booker T. Washington, Madam C. J. Walker foi considerada, por excelência, como "uma das mais progressistas e famosas mulheres da nossa raça" (Côrtes, 2012).

Além de atuar ativamente na causa em prol da população negra, posicionando-se efetivamente contra a superioridade branca, Sarah também protagonizou discursos narrando sua trajetória como mulher negra, filha de escravos (Madalozzo, Martins \& Shiratori, 2021). Em uma palavra realizada na National Negro League Business Convention, em 1912, aduziu que:

Eu sou uma mulher que veio dos campos de algodão do Sul. Lá, fui promovida ao tanque de lavar roupa [e depois] à cozinha. [Da cozinha] eu me autopromovi ao mundo empresarial dos manufaturados e preparações para o cabelo [e assim] eu construí minha própria empresa, no meu próprio chão (Côrtes, 2012, p. 17).

Em outra ocasião, sendo entrevistada pela New York Times Magazine, em novembro de 1917, Walker também narrou que:

Eu fui para Denver, Colorado e comecei minha carreira com um capital de \$1,25. Comecei, é claro, de uma forma mais modesta. Sondava as pessoas da minha raça indo de porta em porta. Depois disso, fui muito bem. Mas, claro, encontrei muitos obstáculos antes de finalmente alcançar o verdadeiro sucesso. Eu não acredito em ganhar chances. Nunca peguei uma num estoque de supermercado. Não sou uma milionária, mas espero ser um dia, não por causa do dinheiro, mas porque poderei fazer muito para ajudar minha raça (Côrtes, 2012, p. 329).

Dessa forma, é possível constatar que Madam C. J Walker atuou efetivamente na causa do empoderamento negro feminino. Com os desenvolvimentos de elixires capilares que ela própria criou destinado a mulheres de cabelos crespos e cacheados, Sarah conseguiu estabelecer uma firma independente, onde conseguiu angariar um patrimônio que garantiu que ela se tornasse a primeira mulher negra milionária dos Estados Unidos.

Madame CJ Walker agarrou seu sonho, conseguir descobrir as oportunidades, neutralizar as interferências externas e tomar decisões ousadas. Tudo isso porque ela confiou no próprio instinto, acreditou em seu potencial.

O mercado estético e da beleza estava permeado por uma proposta de revigoramento da imagem, dos cabelos e, consequentemente, da aparência. Essa proposta era tão marcante que na época foram produzidos slogans com os dizeres: “da cabana à mansão; de escrava à líder social” e “Glorificando nossa feminilidade” (Xavier, 2013). 
Com essas propagandas e com a fabricação de produtos que enalteciam a beleza negra, Sarah conseguiu disseminar mensagens positivas às mulheres negras, incitando a busca pelo sucesso, a resolução de problemas financeiros, o aumento da beleza e autoestima. Esses anúncios e a ideologia perpetrada por Sarah ajudou fortemente a luta dos afro-americanos por respeitabilidade e reconhecimento social feminino (Oliveira, 2011). A Figura 1 demonstra a expressividade da publicidade da Madam C. J. Walker:

Figura 1. Madam C. J. Walker, Mulher Maravilha da Raça.

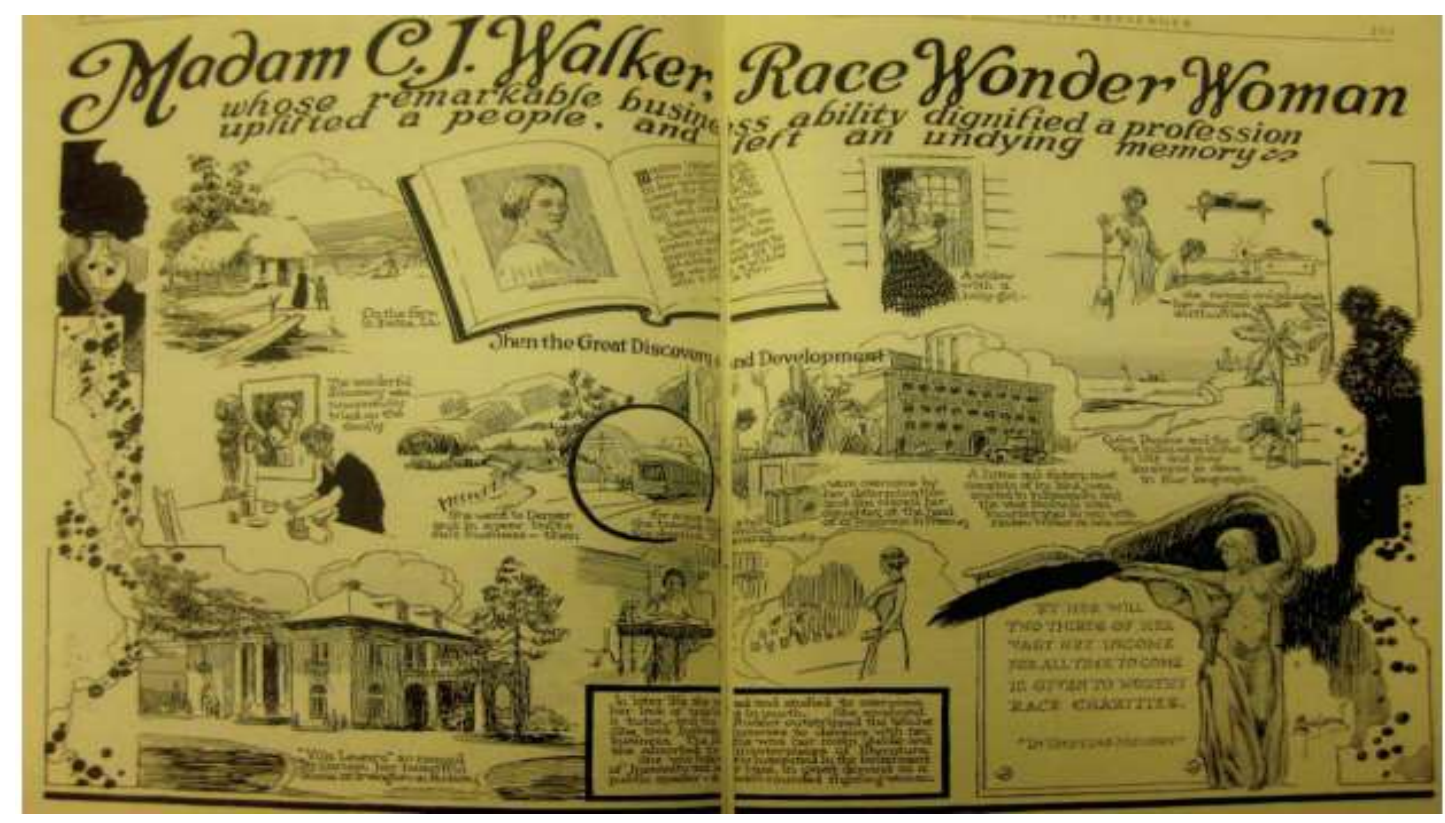

Fonte: Xavier (2013).

Diante disso, Madam C. J. Walker assumiu uma postura empreendedora, pois arriscou-se em um mercado completamente novo. Foi ousada, inovadora, visionária e fundou uma nova ideologia, que foi muito além de ganhos financeiros, mas de empoderamento de mulheres negras. Sarah demonstrou que uma mulher negra pode estar à frente dos negócios e ter resultados positivos iguais ou melhores que de homens.

No caso da empreendedora americana, o investimento no setor de cosméticos para cabelos afro foi um insight. Ela descobriu que poderia ajudar outras mulheres que enfrentavam problemas com o cabelo, como ela própria enfrentou. E, sabendo que outras pessoas tinham essa “dor”, CJ Walker encontrou uma oportunidade perfeita. Apostou então aquele nicho específico: o de mulheres negras que queriam o melhor dos cabelos. E o sucesso estava garantido.

Um ponto fundamental para ser minimamente aceitas depois da escravidão, era uma boa aparência. Esse desejo e perseguição pela boa aparência se uniu a outros movimentos em favor da liberdade racional. Portanto, o mercado de clareamento e alisamento traduziu um dos mais importantes meios para a construção de uma mulher, de cor bonita e reconhecidamente aceitável na sociedade (Xavier, 2013).

Além do desejo de ter uma boa aparência para serem aceitas socialmente, havia outro ponto interessante a ser explanado. Com cabelos bonitos, as mulheres resgatavam a feminilidade perdida nos tempos da escravidão. Dessa forma, para as mulheres afro-americanas, aderir ao cabelo alisado, simbolizava "uma proposta de revitalização da imagem, igualmente calcada no discurso racializado de melhora da aparência, promovido por centenas de cosmetologistas que integravam o time das empresárias da raça.” (Côrtes, 2012, p. 332).

Deste modo, a beleza estava ligada intrinsecamente a ascensão profissional das mulheres afro-americanas. A Madam C. J. Walker potencializava suas vendas, lançando imagens de suas clientes negras bem-sucedidas e enfatizava que as 
“experiências de manipulação dos pelos também revelavam o intento feminino de desconstruir estereótipos através da comercialização e uso de produtos criados para encontrar o penteado mais adequado para representar o que julgavam ser uma beleza cívica negra" (Côrtes, 2012, p. 333).

Enfatize-se que muitos tratamentos e produtos químicos destinados ao alisamento e "amaciamento" dos cabelos afros foram criados pelos próprios negros, objetivando atingir a beleza padrão do momento. A pioneira desse movimento foi a Madam C. J. Walker, que revolucionou a história ao desenvolver uma fórmula para tratar cabelos de mulheres negras (Castro et al., 2021).

Ademais, a busca pelo embelezamento e por cabelos mais bonitos causou uma verdadeira transição capilar, trazendo inúmeros benefícios para a sociedade capitalista. Visando alcançar um ideário de beleza disseminado pela mídia, muitas mulheres se viram manipuladas e começaram a consumir em excesso. A questão principal cinge-se na seguinte problemática: esse padrão de beleza pode alcançado? (Santos, 2000).

Nessa seara de pensamento, as relações consumistas e capitalistas conseguem alcançar até mesmo as categorias sociais mais baixas. Muitas vezes, sem conseguir desenvolver um pensamento crítico - porque são induzidas pela mídia e por publicidades apelativas - algumas mulheres ficam excluídas do meio social. O primeiro motivo: a cor da pele. O segundo: a falta de poder aquisitivo para aderir a todas as demandas e apelações do mercado. Frise-se que algumas mulheres às vezes são levadas a consumir, mesmo quando não há a menor necessidade (Fanon \& Silveira, 2008).

\section{Conclusão}

Conforme exposto no decorrer da pesquisa, Madam C. J. Walker utilizou-se de seus instintos e de forma visionária, ousada e inovadora alcançou sucesso em múltiplos aspectos: financeiro, respeitabilidade, visibilidade da mulher negra e reconhecimento social.

Madam C. J. Walker se aventurou em uma área completamente nova e em uma época em que se imperava o preconceito. Às mulheres negras não existiam outras opções, senão empregos subalternos, sem que pudessem desenvolver seus talentos e estavam sempre à sombra dos brancos, que dominavam a sociedade, mesmo depois da abolição da escravidão.

Com o elixir capilar, Madam C. J. Walker devolveu à incontáveis mulheres não só a beleza e o sonho de uma aparência bonita, mas deu-lhes força e vigor para lutar pelos seus direitos, demonstrar que a mulher pode e merece participar do mercado de trabalho, dos espaços públicos e alçar voos com o empreendedorismo ou no meio acadêmico.

Ao se empoderar e trazer esse empoderamento a outras mulheres, Madam C. J Walker entrou para história como a primeira mulher milionária afro-americana. Além desse legado econômico, ela foi pioneira em devolver e despertar sonhos e deu um novo rumo ao empreendedorismo negro feminino. É neste sentido que este estudo sugere a possibilidade de ampliar a investigação sobre a mulher negra empreendedora no Brasil.

\section{Referências}

Antoniassi Junior, G., \& Figueiredo, G. (2020). Maternidade, graduação e profissão: perfil da mulher na perspectiva do psicodrama. International Journal Of Development Research, pp. 37721 - 37725. https://www.journalijdr.com/sites/default/files/issue-pdf/19194.pdf

Bento, M. (2021). A $\quad$ Mulher $\quad \underset{N}{\text { Negra }} \quad$ no $\quad$ Mercado de $\quad$ Trabalho. Revista Estudos Feministas, (2), 479-488. https://periodicos.ufsc.br/index.php/ref/article/view/16466/15036

Carneiro, S. (2003). Mulheres em movimento. Estudos Avançados, (49), 117-132. https://www.scielo.br/j/ea/a/Zs869RQTMGGDj586JD7nr6k/?lang=pt.

Castro, A. M., Oliveira, E., \& Pereira, G. (2021). Educação Antirracista E Resistência: o cabelo como posicionamento político. Revista Pedagógica, 23, 1-18. https://bell.unochapeco.edu.br/revistas/index.php/pedagogica/article/view/6293.

Constituição Federal (1988). (Brasil). http://www.planalto.gov.br/ccivil_03/constituicao/constituicao.htm 
Côrtes, G. (2012). Brancas de almas negras? beleza, racialização e cosmética na imprensa negra pós-emancipação (EUA, 1890-1930) (tese). UNICAMP. A http://www.repositorio.unicamp.br/handle/REPOSIP/280975.

Fanon, F., \& Silveira, R. da. (2008). Pele Negra, Máscaras Brancas. EDUFBA.

Figueiredo, Â. (2018). Perspectivas e contribuições das associações de mulheres negras e feministas negras contra o racismo e o sexismo na sociedade brasileira. Revista Direito E Práxis, (09), 1080-1099. https://www.scielo.br/j/rdp/a/WFgLzfG77DN7xhh8MLsHMvb/?lang=pt\&format=pdf

Hooks, B. (2015). Mulheres negras: moldando a teoria feminista. Revista Brasileira De Ciência Política, (16), 193 - 210. https://www.scielo.br/j /rbcpol/a/mrjHhJLHZtfyHn7Wx4HKm3k/?lang=pt\&format=pdf

IBGE, Pesquisa Nacional por Amostra de Domicílios 2013. (2021). https://biblioteca.ibge.gov.br/visualizacao/livros/liv94414.pdf

Ludke, M. \& Andre, M. E. D. A. (2013). Pesquisas em educação: uma abordagem qualitativa.

Madalozzo, R., Martins, S., \& Shiratori, L. (2021). Participação no mercado de trabalho e no trabalho doméstico: homens e mulheres têm condições iguais? Revistas Estudos Feministas, (2), 547-566. https://www.scielo.br/j/ref/a/jshjDy5bBjYS9WxgQMgQT7N/?lang=pt\&format=pdf

Momesso, C., \& Hidaka, R. (2021). A trajetória de mulheres de sucesso na área empresarial: uma perspectiva de gênero. Revista Multidisciplinar Do Nordeste Mineiro, (1), 1 - 23. https://revistas.unipacto.com.br/storage/publicacoes/2021/588_a_trajetoria_de_mulheres_de_sucesso_na_area_empresar ial_uma_perspectiv.pdf

Asher, N., J. (Criadora), Davis, D., Oberland, E., \& Cordina, L. (Produtor). (2020). A Vida e a História de Madam C.J. Walker [Mídia de gravação: Minissérie/ Netflix]. País: Estados Unidos.

Oliveira, L. M. A. de. (2011). Beleza E ascensão social na imprensa Negra Paulistana: 1920-1940. PREMIER.

Possatti, I., \& Dias, M. (2002). Multiplicidade de papéis da mulher e seus efeitos para o bem-estar psicológico. Psicologia: Reflexão E Crítica, (2), 293 - 301. https://www.scielo.br/j/prc/a/QKJzcmZ8cNJg39nwSgTm7QG/?lang=pt\&format=pdf

Roland, E. (1993). Mulher negra. Geledés Instituto da Mulher Negra.

Santos, C. E. dos. (2000). Do silêncio do Lar Ao Silêncio Escolar: Racismo, preconceito e Discriminação na Educação Infantil. Humanitas, FFLCH-USP.

Santos, G. (2002). A invenção do "ser negro". Educ / Fapesp.

Xavier, G. (2013, December). Segredos de penteadeira: conversas transnacionais sobre raça, beleza e cidadania na imprensa negra pós-abolição do Brasil e dos EUA. Estudos De História, 26(52), 429-450.

Werneck, J. (2016). Racismo institucional e saúde da população negra. Saúde e Sociedade, 25, 545-549. https://www.scielo.br/j/sausoc/a/bJdS7 R46GV7PB3wV54qW7vm/?lang=pt\&format=html 